\title{
Memórias de corpos esportivizados: a natação feminina e o futebol infame
}

\author{
Luiz Carlos Rigo \\ Eliane Ribeiro Pardo \\ Michele Braun Figueiredo \\ Aline Rodrigues \\ Viviane Teixeira Silveira
}

\begin{abstract}
Resumo: Este artigo toma como eixo para análise e reflexão duas pesquisas sobre as memórias do esporte pelotense - uma referente ao Futebol Menor da cidade e outra à participação das mulheres na natação local -, realizadas pelo grupo de pesquisa Estudos Culturais em Educação Física. Além de destacar as principais singularidades de cada uma delas, este texto procura assinalar certas semelhanças que se mostraram presentes nas memórias dessas duas práticas esportivas, aparentemente tão distintas. Similitudes instituídas, principalmente, por tratarem-se ambas de memórias corporais.
\end{abstract}

Palavras-chave: corpo, memória, esporte.

Estudem, aprendam, certamente sempre restará alguma coisa, mas, sobretudo treinem o corpo e confiem nele, pois ele se lembra de tudo, sem qualquer dificuldade ou impedimento. O que nos distingue das máquinas é unicamente nossa carne divina; a inteligência humana se distingue da artificial apenas pelo corpo. (SERRES, 2004, p. 114)

“Memórias Esportivas: um estudo cartográfico do esporte em Pelotas" é o título dado a um programa de pesquisa sobre as memórias das manifestações esportivas locais, que vem sendo desenvolvido pelo grupo de pesquisa Estudos Culturais em Educação Física da ESEF/UFPel desde agosto de 2002. Inicialmente utilizamos a coleção da Revista dos Esportes (periódico esportivo local, com 120 exemplares, que foram recuperados e digitalizados) para rastrear, mapear, selecionar e analisar imagens e discursos das práticas esportivas da cidade nos anos 40 e 50 . Num segundo momento subdividimos a

1 Esta pesquisa contou com o apoio financeiro da Fapergs e seus autores fazem parte do Grupo de Pesquisa Estudos Culturais em Educação Física da ESEF/ UFPel.

* $\quad$ Professores adjuntos da ESEF/UFPel.

** Bolsista PIBIC CNPq em 2002 e 2003. E-mail: mbraunf@yahoo.com.br

*** Acadêmica da ESEF/UFPel, bolsista do PET. E-mail: liliesef@bol.com.br

**** Bolsista PIBIC CNPq em 2002 e 2003. E-mail: vivisilver@yahoo.com.br

Movimento, Porto Alegre, v. 11, n. 2, p.131-146, maio/agosto de 2005 
pesquisa em quatro frentes e, fazendo uso da metodologia da História Oral, realizamos quatro estudos diferentes, nos quais investigamos o Futebol Menor da cidade, a presença das mulheres na Natação local, a trajetória dos dois principais clubes náuticos da cidade e a história de vida de um timoneiro (seu Adão). O texto que aqui segue é uma síntese de duas dessas frentes de pesquisas (Futebol e Natação) que, entre outros aspectos, têm em comum o fato de ambas terem utilizado como metodologia depoimentos orais (cinco no futebol e quatro na natação) e de tratarem de memórias esportivas corporais contemporâneas, que dizem respeito a um mesmo tempo e a um mesmo lugar: a cidade de Pelotas.

\section{Futebol Infame: memórias menores ${ }^{2}$}

A partir dos anos 20, o futebol torna-se o esporte predominante na cidade de Pelotas. Além de clubes tradicionais, como Grêmio Esportivo Brasil, Esporte Clube Pelotas, Grêmio Atlético Farroupilha e Clube Atlético Bancário, há também uma quantidade enorme de times avulsos e pequenos clubes espalhados pelos diversos bairros, o que ilustra o significado cultural dessa prática em Pelotas, principalmente a partir da segunda década do século XX. ${ }^{3}$

Com o intuito de conhecermos um pouco da história e do significado cultural desse futebol, além das fontes escritas e das inúmeras fotografias (mais de 30), coletamos e fizemos uso de cinco depoi-

2 Os termos futebol infame e futebol menor serão tomados aqui como sinônimos. O primeiro é tomado de empréstimo de Michel Foucault, do sentido que ele adquire no seu trabalho "A vida dos homens infames", (In: O que é um Autor? Lisboa: Vega, 1992.) onde é utilizado para se referir a sujeitos não famosos. Já o segundo termo é utilizado pela Revista dos Esportes, uma das fontes da pesquisa, para designar os times avulsos e os pequenos clubes da cidade. Geralmente clubes de bairros, de fábricas etc.

3 O ano de 1906 pode ser considerado o pioneiro da emergência de clubes esportivos na cidade. É neste ano que são fundados, por exemplo, o Club Sportivo, O Club Sportivo Internacional e o Foot-Ball Club, clubes sociais esportivos que Club Sportivo Internacional e o Foot-Ball Club, clubes sociais esportivos que
ofereciam a prática do futebol. Um pouco mais tarde, em 1913, começa a acontecer anualmente o Campeonato Citadino de Futebol em Pelotas. A partir dessa cer anualmente o Campeonato Citadino de Futebol em Pelotas. A partir dessa mente. Em 1920, por exemplo, a cidade possuía três ligas de futebol que organizavam três diferentes Campeonatos Citadinos. A partir dessa data há uma significativa proliferação de times avulsos, de pequenos clubes de bairros, de clubes de fábricas etc. - fato que pode ser verificado pela variedade de clubes e times de futebol que começam a ter seus nomes registrados nos jornais da cidade na época. Para maiores detalhes sobre a emergência e consolidação do futebol na cidade de Pelotas e região soltán de Fronteira. Pelotas: Editora Universitária UFPel, 2004.

Movimento, Porto Alegre, v. 11, n. 2, p.131-146, maio/agosto de 2005 
mentos orais de antigos amantes da bola. ${ }^{4}$ Desses depoimentos emergiram vários temas; mas, neste artigo, estaremos delegando uma atenção especial às práticas de sociabilidade, bem como à organização e às estratégias utilizadas pelos clubes para alcançarem uma significativa perenidade.

Se, por um lado, muitas vezes, esse futebol emergiu da instituição familiar que ainda hoje o impulsiona (ver figura 01), por outro, imaginá-lo restrito a ela, no que tange às práticas de socialização, seria um equívoco. As narrativas dos nossos entrevistados salientam o fato de esse futebol ser uma oportunidade para ampliar e reforçar os laços de convivência e as relações sociais: "É, a gente tinha uma amizade muito grande. A gente tinha muitos amigos em todas as cidades, todos os bairros e, por incrível que pareça, o cara que jogava futebol tinha tudo na cidade, amizade né." (MILIONÁRIO, 2003).

Nos depoimentos, chamou-nos a atenção também como as experiências futebolísticas narradas constituíram uma espécie de memória transversal entre os boleiros. Havia sempre um leque de lembranças espontâneas, evocadas por nossos narradores, que independiam das particularidades dos depoentes, dos times em que cada um jogou e dos diferentes assuntos por nós abordados. Ou seja, ao analisarmos os depoimentos, percebemos que as lembranças compunham uma espécie de núcleo comum da memória do futebol infame. Nesse núcleo sobressaíram-se as lembranças que provinham das experiências diretamente vinculadas ao jogo, em detrimento daquelas que dizem respeito aos episódios estruturais e organizativos extra campo, por exemplo. Emergiu dos depoimentos uma memória prática do futebol constituída pelas lembranças dos companheiros de equipe (nomes e apelidos), pelos principais adversários (os clássicos de cada bairro), pelos jogadores mais habilidosos, pelas jogadas mais brilhantes, ou, ainda, um campeonato ou torneio que seu time venceu, uma jogada que fez e ficou na lembrança, um gol que marcou, outro que perdeu.

Alguns agenciamentos produtores de subjetividade dessas memórias podem ser percebidos, por exemplo, nos cuidados que os entrevistados demonstraram possuir com a preservação das camisetas, das flâmulas e das fotografias dos times que jogaram,

4 A rede de depoentes da pesquisa do Futebol Infame foi composta pelos seguintes narradores: João Carlos da Cunha, 55 anos, entrevista realizada em 26/12/2003; Nelson Peter, 71 anos, entrevista realizada em 10/02/2003; Paulo Machado, 81 anos, entrevista realizada em 10/02/2003; Blanádio de Oliveira, 71 anos, entrevista realizada em 11/02/2003; Clarinha Bulow Guths, 61 anos, entrevista realizada em 15/04/2003. Todas as entrevistas ocorreram na casa dos entrevistados.

Movimento, Porto Alegre, v. 11, n. 2, p.131-146, maio/agosto de 2005 
objetos que eles guardam como relíquias. Sobre os uniformes, os narradores lembraram que eles eram lavados pelos próprios jogadores ou familiares e, na maioria das vezes, eram adquiridos através de rifas, festas e vísporas. ${ }^{5}$ Seu Milionário (2003) lembrou que o fardamento era dado pela G. E. R. Planalto, ${ }^{6}$ mas lembrou que era raro conseguir outro tipo de ajuda, como passagens de ônibus, por exemplo.

Partindo das questões levantadas anteriormente acerca das práticas esportivas na cidade de Pelotas e da forma como elas se multiplicaram e se consolidaram nos anos 40 e 50, intervindo na produção de uma determinada subjetividade dos cidadãos pelotenses, podemos dizer que, ao rememorar a experiência de alguns personagens dessas práticas, tornou-se possível entender o lugar de destaque que esse futebol ocupa, ainda hoje, na cultura futebolística da cidade. Porém, é fundamental destacar que a tradição e a perenidade alcançada por ele não foi uma mera conseqüência do acaso, ela contou com o esforço e participação de inúmeros militantes anônimos da bola.

A potência desse futebol que, entre outros fatores, se mostrou capaz de criar entre seus adeptos uma memória compartilhada própria do futebol infame, aliada com o grande número de pequenos clubes e times avulsos que insistem em existir em condiçốes adversas atestam que o Futebol Menor de Pelotas está longe de desaparecer. Semelhante ao que ocorre em outras cidades, como muito bem diagnosticou Flávio Adauto (1999), esse futebol não morreu, ele apenas "mudou de lugar". Ele se deslocou do centro da cidade para as vilas e para os bairros mais periféricos. E, como assinala esse mesmo autor, "ainda são muitos os campos de várzea, milhares os times, muitos deles com 50,60,70 anos de vida sem nunca interromper suas atividades" (ADAUTO, 1999, p. 122). Em Pelotas, por exemplo, é enorme o número de times que todos os finais de semana entra em campo tanto nos bairros como na zona rural da cidade.

5 Jogo com cartões numerados; uma espécie de bingo.

6 Grêmio Esportivo Recreativo Planalto, fundado em 10/11/1930,é um Clube esportivo social tradicional do Futebol Menor da cidade, sua sede está situada no Bairro Areal.

7 Enquanto os times da zona urbana costumam disputar jogos amistosos e o Campeonato Varzeano, organizado pela Liga Pelotense de Futebol Amador, os times da zona rural além dos amistosos participam dos Campeonatos da Colônia, que hoje são organizados por três diferentes ligas: a A.C. P. (Associação Colonial de Pelotas, fundada em 1965), a A. D. C. P. (Associação Desportiva da Colônia de Pelotas, fundada em 1980) e a A. C. E. (Associação Colonial Esportiva, fundada em 1994).

Movimento, Porto Alegre, v. 11, n. 2, p.131-146, maio/agosto de 2005 
Esse deslocamento do Futebol Menor para os arrabaldes indica também que os espaços de socialização da cidade se diversificaram, se multiplicaram, tornando-se cada vez menos restritos ao centro, ou, pelo menos, a um único centro, fazendo com que "as relações entre o centro e a periferia comecem a inverter-se", na medida em que "na estrutura policêntrica da região urbana se destacam os processos simultâneos de concentração e de dispersão, fugindo do modelo tradicional centro e periferia" (PRIGGE, 2002, p. 57).

Através das fontes escritas (Revista dos Esportes), da oralidade e das fotografias foi possível conhecermos um pouco mais as memórias do futebol na constituição cultural da cidade e perceber que, assim como os prédios históricos, os museus, as bibliotecas e os monumentos, o Futebol Menor também faz parte da memória e do patrimônio cultural de Pelotas. Além de ser um espaço propenso à multiplicidade, ele agencia sociabilidades e é atravessado por afetos e valores. O espaço do futebol configura-se como uma prática constituída por tensões e por "relações de poder", ${ }^{8}$ no qual é possível aprender a lidar com as rivalidades, as vitórias e as derrotas.

\section{Memória da tradição}

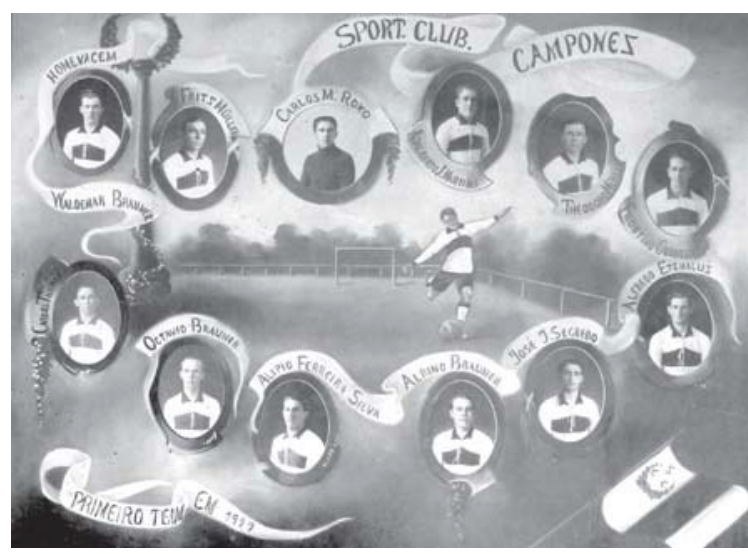

Da esquerda para a direita: Waldemar Brauner; Frits Müller; Carlos M. Roxo; Adalberto J Martins; Theodoro Müller; Frontino Cornettei; Carlos Tillman; Octavio Brauner; Alipio Ferreira Silva; Albino Brauner; José J. Segredo; Alfredo Etchaluz. (Primeiro Quadro - 1922).

Foto: Acervo Particular Nelson Peter.

8 Usamos o conceito de "relações de poder" no sentido que ele é concebido por Michel Foucault, o poder como algo que não é propriedade de ninguém e que se constitui a partir das relações sociais, estabelecendo parcerias com as diferentes áreas do saber e formas de governo. Para mais, consultar do próprio autor: " $O$ sujeito e o Poder", 1995 e "História da sexualidade I": a vontade de saber, 1988.

Movimento, Porto Alegre, v. 11, n. 2, p.131-146, maio/agosto de 2005 
O Sport Club Camponês é um representante típico da tradição do Futebol Menor pelotense. Fundado em 10/10/1910, ele é remanescente da primeira geração de clubes de futebol da cidade, contemporâneo ao Grêmio Esportivo Brasil (1911) e ao Esporte Clube Pelotas (1908). Com a sede social e o campo sempre situados em um bairro de colonização alemã (Bairro Três Vendas), ambos, clube e time de futebol, trazem consigo traços culturais dessa etnia, fato que pode ser percebido na fotografia acima, pela presença de jogadores fato que pode ser per com sobrenomes de descendencia alemã. A presença da instituição familiar na gênese do clube foi outro aspecto destacado por Nelson Peter durante seu relato oral. Na fotografia isso se evidencia pela presença de jogadores com os mesmos sobrenomes: Brauner (três) e Müller (dois).

Figura I. Equipe do Sport Club Camponês, 1922.

\section{Mulheres esportistas}

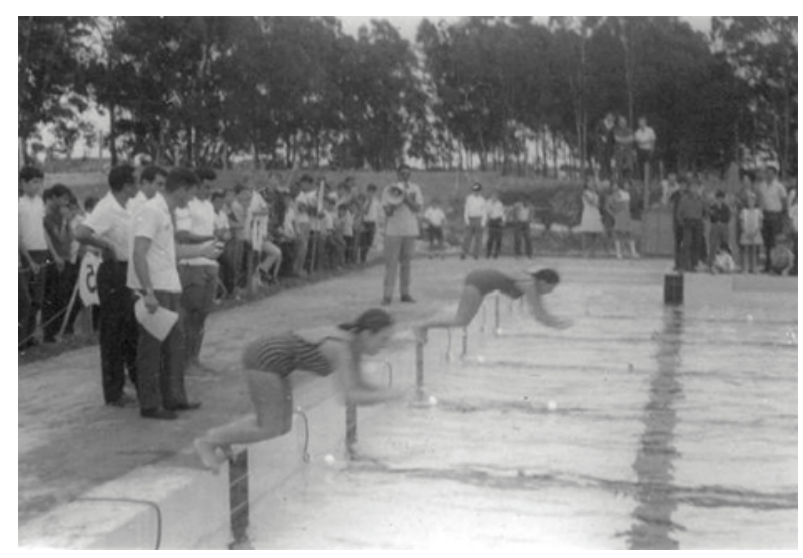

Evento realizado por ocasião da inauguração da Piscina Olímpica (50 m) do Clube Gonzaga, onde vemos as nadadoras Alda Regina Thomás e Maria Helena Thomás. A construção de piscinas apropriadas para as competições esportivas, nos principais clubes da cidade, faz parte do processo de esportivização da natação pelotense (feminina e masculina).

de esportivização da natação pelotense (feminina

Figura II: Inauguração da Piscina do Clube Gonzaga

De maneira geral é possível visualizar na própria historiografia do esporte que o campo esportivo moderno emergiu e consolidou-se como um reduto da cultura masculina. Essa concepção segregacionista sustentou-se tanto em discursos biológicos quanto sociais, como, por exemplo, nos argumentos que conclamavam serem as práticas esportivas impróprias para as mulheres por desenvolverem a virilidade, a coragem, a competitividade, a força e a resistência - qualidades na época socialmente referendadas e indicadas apenas para os homens. Nesse sentido, as mulheres de todas as idades foram con-

Movimento, Porto Alegre, v. 11, n. 2, p.131-146, maio/agosto de 2005 
vidadas a compartilhar desse moderno, "civilizado" e "culto" hábito eurocêntrico do Ser Esportivo, que alcançou a cultura urbana a partir das primeiras décadas do século XX, inicialmente apenas como assistente (espectadora). ${ }^{9}$

Um pouco mais tarde, por volta dos anos 30, fomentado pelo alcance que conseguiram certas modalidades esportivas como o Turfe, o Remo, a Natação e, principalmente, o Futebol (que já não era mais exclusividade das elites), o hábito de exercitar, movimentar e mostrar o corpo torna-se cada vez mais um costume, da maioria das médias e grandes cidades brasileiras.

Somados ao cultivo de certas práticas esportivas, os discursos higienistas e eugenistas em ascensão contribuem para reconfigurar o lugar e o papel do homem e da mulher diante das práticas corporais e da Educação Física. Assim como o homem, a mulher também é convidada a exercitar seu corpo e até mesmo a praticar certas modalidades esportivas, desde que sejam aquelas tidas como compatíveis com o gênero feminino. Os discursos sociais agora em voga "convidam" a mulher a deixar de ser apenas assistente e iniciar-se também no mundo esportivo, desde que esta prática contribua para a aquisição de valores, hábitos e biotipos que facilitem para ela o desempenho de seus dois principais papéis sociais: esposa e mãe. ${ }^{10}$

É em torno desse contexto sociocultural brasileiro, típico dos anos 30 e 40, que um número significativo de mulheres passa a praticar a natação de forma mais sistemática em nosso país. Em função de certas singularidades, (positividades atribuída pelos discursos biológicos e o fato da prática, geralmente, ocorrer em clubes sociais reservados) a natação era vista como uma das modalidades esportivas mais apropriadas e indicadas para o sexo feminino. ${ }^{11}$

9 Sobre os estereótipos atribuídos aos sexos feminino e masculino, ler: ROSEMBERG, Fúlvia. A Educação Física, os Esportes e as Mulheres: Balanço da Bibliografia Brasileira. In: ROMERO, Elaine (Org.). Corpo, Mulher e Sociedade. Bibliografia Brasileira. In: ROMERO, Elaine (Org.). Corpo, Mulher e Sociedade. São Paulo: Papirus, 1995. Consultar também: GOELLNER, Silvana. A Educação Revista Movimento. Ano VII, n. 13, 2000/2.

10 Nesse período as mulheres serviam como referências fundamentais ao engrandecimento do país. As suas representações estavam voltadas para o fortalecimento da raça no que diz respeito à saúde, ao vigor físico. Maiores detalhes sobre o discurso eugênico presente no país podem ser encontrados em: GOELLNER, Silvana. Bela, Maternal e Feminina: Imagens da Mulher na Revista Educação Physica. Ijuí: Ed. Unijuí, 2003. (Mais especificamente o Capítulo "Seja Mãe").

11 “...a natação e os seus anexos, a arte de saltar na água e mergulhar são muito mais 'femininos' do que quaisquer outros esportes. (...) Outro motivo de constituir a água, essa 'irmã gêmea do exercício', o ambiente especialmente adaptado às mais esplêndidas façanhas femininas é que elas sentem, instintivamente umas,

Movimento, Porto Alegre, v. 11, n. 2, p.131-146, maio/agosto de 2005 
A seguir, fazendo uso da memória de nadadoras pelotenses, tentaremos mostrar um pouco do modo como essas mulheres viveram essa época e como essa experiência atuou de forma significativa na constituição da subjetividade feminina. ${ }^{12}$

\section{Maiôs de babados e brocados: histórias de mulheres que nadam}

O que me marcou mais foi uma vez em Porto Alegre, quer dizer [...] eu caína água - eram todas favoritas lá - eu caí na água sem conhecer ninguém [...]. E depois, a outra foi em 53: quando eu caí na água eu era magrinha, fininha [...] pesava $49 \mathrm{~kg}$. Eu tremi, minhas pernas tremiam, mas eu disse: Bom! Agora vai! Dei tudo! Chegueia ganhar, quer dizer [...] essas coisas me marcam. (CHUTECA, 2003).

Os quatro depoimentos orais ${ }^{13}$ que coletamos nos revelaram peculiaridades, curiosidades e detalhes importantes das experiências dessas mulheres com a natação, com a vida social dos clubes, com os familiares, com a cidade, com seus corpos e com a técnica e com o treinamento típico da época, confeccionando, a partir da memória,

conscientemente outras, que a natação tem capacidade morfogênica incomparável, construtora - como nenhum outro esporte - da harmonia plástica do corpo e inspiradora da graça dos seus Sports (1920, p. 25), intitulado "A mulher e a agua". In: SCHPUN, Mônica. Beleza em jogo: Cultura física e comportamento em São Paulo nos anos 20. São Paulo: Boitempo Editorial/SENAC, 1999. Sobre esta temática, consultar: MOURÃO, Ludmila. Representação social da mulher brasileira nas atividades físicodesportivas: da segregação à democratização. Revista Movimento, Ano VII, n.13.

12 Por ser uma cidade portuária, de significativa expressão econômica no Rio Grande do Sul do início do século XX. Pelotas foi também um dos principais polos esportivos do Estano e do Pais. Assim, junto com o futebol, os esportes aquáticos (remo e natação) tiveram significativo destaque esportivo na cidade,
principalmente na primeira metade do século XX.

3 As quatro ex-nadadoras entrevistadas fizeram parte da história da natação na cidade de Pelotas e aparecem citadas nos exemplares da Revista dos Esportes. Laura Teixeira, 60 anos, foi entrevistada no escritório onde trabalha juntamente com o ex-marido e com o filho. Mostrou muito interesse em nos auxiliar e se propôs a realizar outras entrevistas. Carmem Passos Decker, 71 anos, foi uma das pioneiras no esporte local, sendo bicampeã de natação pelo Náutico Gaúcho, detentora de vários recordes femininos. Nos concedeu a entrevista em suacasa. Helena Passos Stoch, 67 anos, foi Campeã Gaúcha de Natacão em 1952. casa. Helena Passos Stoch, 67 anos, foi Campea Gaúcha de Natação em 1952. Começou a praticar o esporte influenciada pelas vitórias da irmã; obteve grandes triunfos e reconhecimento da cidade. Foi a mulher mais presente nos exemplares da Revista dos Esportes, sendo inclusive a única capa feminina da Revista. Foi entrevistada em sua casa, e seu marido Adalberto Stoch estava presente ajudando a trazer lembranças. A outra é Alda Regina Thomás, 53 anos. Foi entrevistada em sua casa juntamente com sua irmã Maria Helena Thomás, que auxiliou no resgate de algumas memórias.

Movimento, Porto Alegre, v. 11, n. 2, p.131-146, maio/agosto de 2005 
uma versão bastante singular acerca da mulher nas práticas esportivas, mais especificamente na natação pelotense.

Cabe aqui uma ressalva: esta pesquisa sempre tentou desviar-se de toda a produção teórica que coloca a mulher no lugar de um "outro" na prática histórica de dominação masculina, e aproxima-se da produção que a vê em sua singularidade de mulher, distanciando-se dos condicionantes sociais e históricos que a configuram em suas funções de fêmea, mãe e esposa. ${ }^{14}$ Apesar disso estereótipos e preconceitos quanto aos papéis sociais da mulher - e mais especificamente das mulheres nadadoras - direta ou indiretamente marcaram de modo significativo os relatos de nossas entrevistadas.

As mulheres nadadoras não ficaram alheias, por exemplo, ao chamado social de mãe e esposa (casar e ter filhos), estipulados para elas nos anos 30, 40 e 50 e essa condição, interferia na vida atlética das nadadoras. Uma das nossas entrevistadas, ao falar sobre esse assunto, observou que a maioria das nadadoras paravam de praticar o esporte quando se casavam. Isso acontecia em parte pela visibilidade que o esporte lançava sobre a mulher atleta que, ao casar-se, ao invés de incentivo, geralmente encontrava, da parte de seu companheiro, apelos para deixar a natação, principalmente a de caráter competitivo. Foi o que aconteceu, por exemplo, com Laura Teixeira (2003): “Nadei até os dezoito, depois eu casei, e aí o marido já disse que eu não ia nadar mais, que agora eu tinha que cuidar da casa."

As restrições às práticas esportivas encontravam suas justificativas em discursos normativos que abrangiam os cuidados especiais que a mulher deveria ter com o desenvolvimento muscular, com seus excessos maléficos para o corpo - que deveria se destinar apenas à maternidade - e até mesmo com a vestimenta esportiva adequada já que existia um olhar vigilante com as roupas que as mulheres nadadoras usavam em público, mesmo sendo os maiôs abundantes em tecidos, dobras e babados.

Naquela época duas-peças era malvisto. Eu me lembro uma ocasião que uma senhora de Porto Alegre, que veio para cá com o marido, ela remava, e veio com um maiô de duas peças, nem era biquíni. Ah! Foi assim, todo mundo: ah. barriga de fora! (PASSOS, 2003).

As imagens presentes nas revistas permitem visualizar que os limites impostos quanto ao tamanho dos maiôs expressam um pouco do tensionamento e da ambigüidade, que caracterizava a prática da

14 Para mais informações, ver: LOURO, Guacira Lopes. Teoria Queer - uma política pós-identitária para a educação. Revista Estudos Feministas CFH/CCE/UFSC, v.9, n. 2, p. 541-553, 2001.

Movimento, Porto Alegre, v. 11, n. 2, p.131-146, maio/agosto de 2005 
natação feminina naquele momento: ao mesmo tempo em que a prática esportiva passava a ser aceita e mesmo incentivada, os discursos e as táticas de controle e vigilância - como elas deveriam se comportar, dentro e fora das piscinas, e sobre a exposição do corpo da mulher nadadora continuaram existindo.

Por ser uma das modalidades esportivas em que a participação da mulher era mais aceita (menor resistência), paulatinamente a natação feminina começou a aparecer como um hábito esportivo de jovens da classe média e alta, principalmente entre aquelas em que havia um certo incentivo familiar. Alda Regina Thomás (2003) nos contou que a sua iniciação na natação não foi muito difícil. Além de a maioria das competições ocorrerem apenas entre familiares ou amigos ela comentou que a intensidade nas competições da época era bastante diferente da atual. Como não havia ainda se instaurado na natação feminina um grau de competitividade tal qual vemos hoje, as disputas eram mais amenas. "A gente nadava assim(...)Os outros clubes não tinham muitas nadadoras. Então nós nadávamos irmã com irmã e já estipulávamos: tal prova uma vai ganhar o primeiro, e a outra, o segundo. Na outra prova a outra ganha", (THOMÁS, 2003).

Além das questões que dizem respeito aos papéis sociais atribuídos às mulheres nadadoras, outro assunto que emergiu e nos chamou atenção nos depoimentos coletados se refere às condições financeiras e infra-estruturais, e à existência ou não de apoios (patrocínios) às mulheres que praticavam a natação nos anos 40 e 50 . Na época o amadorismo era a filosofia que reinava absoluta na natação. Carmem Passos (2003) lembrou que, assim como ela, também as outras nadadoras tinham um grande orgulho de serem atletas amadoras: "Não era profissional, não, era amor ao esporte mesmo; e eu tinha paixão por natação".

Os dois principais clubes da cidade nos Esportes Náuticos (Remo e Natação), na época, eram o Regatas Pelotense (1914) e o Náutico Gaúcho (1932). ${ }^{15} \mathrm{O}$ ambiente configurado nesses clubes, conforme rememorado pelas antigas nadadoras, lembrava um clima familiar, um espaço formado por amigos ou por sujeitos de uma mesma classe social - características típicas dos clubes esportivos amadores. De acordo com uma das nossas entrevistadas, essas disposições configuravam os clubes como espaços mais confiáveis com menos

15 Um estudo mais detalhado sobre a trajetória desses dois clubes e suas respectivas interferências na cultura esportiva da cidade encontra-se no artigo de Aline Nunes da Cunha "Um estudo genealógico dos clubes de Remo em Pelotas: Regatas Pelotense e Náutico Gaúcho", 2004. Pesquisa inserida no programa "Memórias Esportivas: um estudo cartográfico do esporte em Pelotas".

Movimento, Porto Alegre, v. 11, n. 2, p.131-146, maio/agosto de 2005 
preconceitos e discriminações com as atletas. "Então eu nunca senti nenhuma diferença. Nós, naquela época, éramos poucas a nadar, éramos conhecidas. Na época todo mundo conhecia as irmãs Thomás. Era o xodó, né?" (THOMÁS, 2003).

Em razão das práticas esportivas intervirem diretamente na saúde, nos hábitos e na estética feminina (beleza, contornos corporais), assinalando diferenças significativas em relação às mulheres de modo geral, os corpos dessas esportistas tornaram-se um objeto em questão. Enquanto certos esportes, como a natação, a equitação e o tênis, admitiam a presença das mulheres, desde que controlados os seus excessos, outras práticas esportivas eram taxativas em seus discursos hegemônicos e prescritivos: para que não perdessem suas clássicas imagens e padrões corporais de feminilidade, as mulheres deveriam evitar, acima de tudo, os jogos másculos.

Ao coletarmos os depoimentos, observamos a ressalva de nossas entrevistadas em relação às competições esportivas femininas por elas apresentadas como espaços nos quais era possível visualizar a mulher atleta como um ser capaz de congregar beleza, graça, corpos delineados, força e virilidade sem se tornar masculinizada, mas ressaltando, ao invés disso, sua feminilidade.

Mesmo que nossos diagnósticos tenham apontado esse movimento de inserção e consolidação da mulher na natação pelotense como um processo progressivo marcado pela ausência de maiores tensões e confrontos imediatos com os valores sociais da época, ainda assim é possível assinalar a sua importância no que tange a modificações significativas no ethos esportivo da época, tensionando o universo esportivo, configurado até então como um território exclusivo do reino masculino.

Se os discursos mais aceitos socialmente passaram a incentivar a participação da mulher na natação, favorecendo uma conseqüente exibição e exercício do corpo feminino, mais do que coexistir com outros discursos, eram eles próprios discursos de controle e vigilância desses mesmos corpos.

No entanto, a despeito de toda forma sutil ou não de vigilância e controle, essas mulheres nadadoras confirmaram, em suas narrativas, ser a natação um espaço de sociabilidade e de fortalecimento dos laços de amizade. As suas memórias dos tempos de atleta pulsam no presente como uma espécie de resistência silenciosa, saudosas daquelas competições que foram um espaço pioneiro para o corpo feminino congregar beleza, graça, corpos delineados, força e perseverança.

Movimento, Porto Alegre, v. 11, n. 2, p.131-146, maio/agosto de 2005 


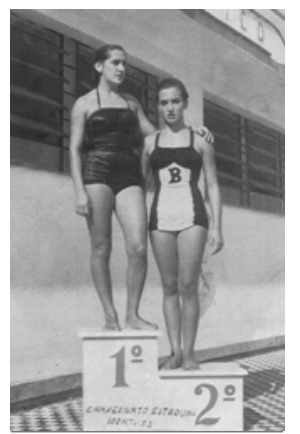

Em destaque a vestimenta e o pódio, marcas da esportivização da natação feminina. Em primeiro lugar Helena Passo (Chuteca), nadadora pelotense de renome estadual.

Fotografia: Acervo particular de Carme Passos.

Figura III. A esportivização da natação feminina.

\section{Considerações finais: o gesto narrado corporifica a memória}

O que poderia existir em comum nas memórias de futebolistas anônimos e de nadadoras pioneiras? Num primeiro plano, poderíamos destacar que em ambas há memórias esportivas atravessadas de modo peculiar pela problemática do corpo. Em todas as rememorações das experiências sobressaía-se uma memória do corpo, atualizada na maneira própria de narrar, trazendo para a cena da palavra narrada a presença marcante do gesto que descreve uma lembrança e destaca temas, ora a visão social do corpo das nadadoras; ora as exigências técnicas, táticas e físicas requisitadas aos praticantes do Futebol Menor; ora as características dos treinos; e o condicionamento físico exigido para ambas as modalidades esportivas.

Assim podemos dizer que a forte presença física do gesto na narrativa de nossos depoentes, nas descrições minuciosas das cenas vividas, singulariza e encharca de corpo as lembranças esportivas, configurando uma espécie de memória dos modos do viver corpóreo que traz para o centro do plano configurado as formas históricas culturais de exercitar, excitar e manifestar publicamente o corpo, memórias do corpo que lembram as técnicas corporais descritas por Marcel Mauss (1968). ${ }^{16}$ Nessa memória as cicatrizes corporais testemunham a intensidade da prática esportiva, experiência moderna que ao longo do século XIX,

16 Marcel Mauss chama de Técnicas Corporais o registro corporal dos códigos e das singularidades das diferentes culturas. Maiores considerações consultar: MAUSS, M. Das Técnicas Corporais In: LEVÍ-STRAUSS, C. Sociologia e Antropologia como uma introdução a obra de Marcel Mauss. São Paulo, EPU, 1974.

Movimento, Porto Alegre, v. 11, n. 2, p.131-146, maio/agosto de 2005 
XX e XXI vêm constituindo um concepção singular de corpo: o corpo esportivizado. Nas lembranças dos esportistas acentuouse o que sinalizou Michel Serres, quando destacou que "o corpo não recebe ajuda de qualquer memória externa, ele o faz por si só, copia e armazena os dados" (2004, p. 76).

Além do corpo, outra força presente nas narrativas de nossos depoentes diz respeito à composição singular da memória esportiva: os ingredientes constitutivos das lembranças dos esportistas/narradores. Numa espécie de narrativa simbiótica, nossos depoentes alternavam gestos, palavras, imagens, objetos (recordações dos companheiros de equipe, adversários, treinos, competições, excursões esportivas, fotografias, camisetas, flâmulas, faixas, diplomas esportivos, medalhas, carteiras sociais). Ao adquirir importância na narrativa, derivando outras histórias, cada um desses objetos subjetiva a memória, articulando a experiência pessoal ao socius de modo radical, pelo sentido atribuído ao episódio vivido, atualizado no objeto guardado. A medalha de determinada competição, a camiseta de tal time etc., no seu conjunto, formavam aquilo que Peter Stallybras (1999) chamou de uma "Memória Material".

Cada uma dessas lembranças materiais ganham uma vida própria. As fotografias, por exemplo, geralmente amassadas e amareladas pelo tempo, muito mais do que as suas qualidades técnicas/estéticas universais, têm seu valor mensurado por aquilo que elas representam para seus proprietários; seu valor possui, assim, um sentido ético/estético, quase que exclusivamente particular. ${ }^{18}$ Assim como as fotografias, todos os outros objetos esportivos, guardados com tanto zelo por nossos narradores, seguem essa mesma lógica, ou seja, seu valor independe do material de que são construídos ou mesmo de determinados padrões estéticos; envelhecidos juntamente com seus proprietários, eles

17 Peter Stallybras utiliza o conceito de "Memória Material" com o intuito de destacar que as memórias não são apenas formadas pelas dimensões abstratas da
consciência individual, o autor argumenta que as memórias se constituem, princonsciência individual, o autor argumenta que as memórias se constituem, principalmente, pelas relações sociais e também pelas relações que estabelecemos com certos objetos materiais, como as nossas roupas, por exemplo. Para mais consultar: STALLYBRASS, P. O casaco de Marx: roupas, memória, dor, 1999.

18 Quanto às fotografias, chamou-nos a atenção os cuidados com que seu Milionário guardava em sua casa um álbum de fotos dos times do Futebol Menor da cio guardava cidade. Nem todas eram fotografias originais, algumas eram fotocópias em preto-e-branco de baixa qualidade. Quando perguntado sobre o significado das otografias e sobre como ele as conseguiu, respondeu-nos que muitas ele havi ganho de colegas do futebol, seus amigos sabiam que ele costumava guardar, pelo menos, uma fotografia de cada um dos times no qual ele jogava.

Movimento, Porto Alegre, v. 11, n. 2, p.131-146, maio/agosto de 2005 
extrapolam os códigos sociais universais de valor para tornarem-se o que Violette Morin apud Bosi (2003, p.26) denomina de "objeto biográfico", que são aqueles objetos que se incorporam à vida e à memória de seus proprietários. Nesse caso, o seu valor é de foro íntimo, diz respeito apenas ao seu dono, familiares e amigos, apenas àqueles que compartilharam vidas e memórias.

Já num plano mais transversal da memória, o próprio texto revela que em ambas as práticas, futebol e natação, há uma série de afinidades, marcas intrínsecas, que permeiam a própria historiografia do esporte moderno. Nesse sentido é possível visualizar como a sociabilidade é um tema que atravessa tanto as memórias da natação como as do futebol. Além disso, há nas lembranças dos (as) narradores (as) uma série de referências que remetem a uma sociabilidade produzida em experiências localizadas, composta de devires singulares que configuram modos de subjetivações característicos, como é o caso da instituição familiar e da segregação por gênero, por exemplo. Dois traços de subjetivações típicos da sociabilidade produzida pelos Esportes Modernos que, como vimos, estiveram presentes tanto nas memórias do Futebol Infame como nas da Natação feminina, embora não necessariamente com a mesma intensidade.

Memories of the sportive body: female swimming
and infamous soccer
Abstract: For questions of analysis and reflection, this
article is based on two researches on the memoirs of
sports in Pelotas - one referring to the Lesser Soccer in
the city and the other to the participation of women in
local swimming - carried out by the research group
Cultural Studies in Physical Education. Apart from
detailing the principal singularities of each one, this
text aims at determining similarities that are shown to
be present in the memoirs of these two sports practices,
which are apparently different from one another.
Instituted similarities, principally, because both deal with
corporal memoirs.
Keywords: body, memoir, sport.

Movimento, Porto Alegre, v. 11, n. 2, p.131-146, maio/agosto de 2005 
Recuerdos de cuerpos deportizados: la natación feminina y el fútbol despreciable

Resumen: Este artículo toma como eje para analisis y reflexión dos pesquisas sobre las memorias del deporte en la ciudad de Pelotas - una referente al Fútbol Menor de la ciudad y otra a la participación de las mujeres en la natación local - realizada por el grupo de pesquisa Estudios Culturales en Educación Física. Además de destacar las principales singularidades de cada una de ellas, este texto busca apuntar ciertas semejanzas que mostraranse presentes en las memorias de esas dos prácticas deportivas, aparentemente tan distintas. Similitudes instituídas, principalmente, por tratarense ambas de memorias corporales.

Palabras clave: Cuerpo, memoria, deporte

\section{Referências}

ADAUTO, F O Futebol da cidade não morreu só mudou de lugar In: DA COSTA, M. Regina ... et al. (Org.). Futebol: Espetáculo do século. São Paulo: Musa Editora, 1999. p. $119-127$.

BOSI, E. O tempo vivo da memória: ensaios de psicologia social. São Paulo: Ateliê Editorial, 2003.

CUNHA, A. N. Um estudo genealógico dos clubes de Remo em Pelotas: Regatas Pelotense e Náutico Gaúcho. In: GII, L. A. LONER, B. A.; MAGALHÃES, M. O. (Orgs). Horizontes Urbanos. Pelotas, 2004. p. 182-201.

FOUCAULT, M. A Vida dos Homens Infames. In: O que é um autor? Lisboa: Vega, 1992. p.89 - 128. 1988.

sujeito e o poder. In: DREYFUS, H.; RABINOW, P. Michel Foucault: uma trajetória filosófica (para além do estruturalismo e da hermenêutica). Rio de Janeiro: Forense Universitária, 1995.

GOELLNER, S. Bela, Maternal e Feminina: Imagens da Mulher na Revista Educação Physica. Ijuí: Ed. Unijuí, 2003.

A Educação Física e a construção de imagens de feminilidade no Brasil dos anos 30 e 40. Revista Movimento, Ano VII, n.13. 2000/2. p. 61 -70.

LOURO, G. L. Teoria Queer - uma política pós-identitária para a educação. Revista Estudos Feministas CFH/CCE/UFSC, v. 9, n. 2, 2001. p. 541-553.

Movimento, Porto Alegre, v. 11, n. 2, p.131-146, maio/agosto de 2005 
MAUSS, M. Das Técnicas Corporais In: LEVÍ-STRAUSS, C. Sociologia e Antropologia como uma introdução a obra de Marcel Mauss. São Paulo, EPU, 1974. p. $209-233$

MOURÃO, L. Representação social da mulher brasileira nas atividades físicodesportivas: da segregaçã̃o à democratização. Revista Movimento, Ano VII, n. 13. $2000 / 2$. p. $5-18$

PRIGGE, W. Metropolização. In: PALLAMIN, Vera M. (Org.). Cidade e cultura: esfera pública e transformação urbana. São Paulo: Estação Liberdade, 2002. p. 51-59.

RIGO, L. C. Memórias de Um Futebol de Fronteiras. Pelotas: Editora Universitária, UFPel, 2004.

ROSEMBERG, F. A Educação Física, os Esportes e as Mulheres: Balanço da Bibliografia Brasileira. In: ROMERO, Elaine (Org.). Corpo, Mulher e Sociedade. São Paulo: Papirus, 1995. p. 271 - 308.

SCHPUN, M. Beleza em jogo: Cultura física e comportamento em São Paulo nos anos 20. São Paulo: Boitempo Editorial /SENAC, 1999.

SERRES, M. Variações sobre o corpo. Rio de Janeiro: Bertrand Brasil, 2004.

STALLYBRASS, P. O casaco de Marx: roupas, memória, dor. Belo Horizonte: Autêntica, 1999.

\section{Revistas}

Revista dos Esporte. Ano IV, n. 39. Pelotas, 1952

Revista dos Esporte. Ano V, n. 42. Pelotas, 1952.

\section{Entrevistas:}

Laura Martins Teixeira, 2003.

Carmem Passos Deker, 2003.

Alda Regina Thomás, 2003.
Helena Passos Stoch, 2003.

Nelson Peter, 2003.

Blanádio de Oliveira (Milionário), 2003.

Clarinha Bulow Guths, 2003.

João Carlos da Cunha, 2003.

Paulo Machado, 2003.

Data entrega:27.01.05 Data parecer:14.02.05

Luiz Carlos Rigo Universidade Federal de Pelotas. Escola de Educação Física e-mail:Icrigo@terra.com.br Eliane Ribeiro Pardo - elipardo@terra.com.br Michele Braun Figueiredo -mbraunf@yahoo.com.br Aline Rodrigues-liliesef@bol.com.br Viviane Teixeira Silveira - vivisilver@yahoo.com.br

Movimento, Porto Alegre, v. 11, n. 2, p.131-146, maio/agosto de 2005 